\title{
Cloning, nucleotide sequence and heterologous expression of the protective outer-membrane protein P.68 pertactin from Bordetella bronchiseptica
}

\author{
Jingli Li, $\dagger$ Neil F. Fairweather, Pavel Novotny, Gordon Dougan $\ddagger$ and Ian G. Charles* \\ Wellcome Research Laboratories, Langley Park, Beckenham, Kent BR3 3BS, UK
}

(Received 11 February 1992; revised 21 April 1992; accepted 7 May 1992)

\begin{abstract}
The prn gene encoding the $68 \mathrm{kDa}$ protective outer-membrane protein of Bordetella bronchiseptica (P.68 pertactin) was cloned, sequenced and expressed in Escherichia coli. The gene was isolated by DNA:DNA hybridization experiments using a radioactively-labelled fragment of the homologous prn gene from Bordetella parapertussis. DNA sequence analysis reveals that the gene is capable of encoding a protein with a molecular mass of $93996 \mathrm{Da}$ (P.94); this precursor molecule is processed to form the P.68 antigen on the surface of $B$. bronchiseptica. Heterologous expression of the full-length gene encoding P.94 in Escherichia coli results in similar processing, with the P.68 antigen targeted to the bacterial outer membrane. Comparison of P.94 with the P.93 and P.95 precursors, encoding homologous proteins from Bordetella pertussis and $B$. parapertussis, shows a high degree $(>90 \%)$ of homology. The major differences between all three proteins occur in the number of repeats of the two families (GlyGly-Xaa-Xaa-Pro $)_{n}$ and (Pro-Gln-Pro) ${ }_{n}$ of reiterated sequence motifs.
\end{abstract}

\section{Introduction}

Bordetella bronchiseptica (Pittman, 1984) is a bacterial pathogen associated with respiratory diseases in animals, particularly atrophic rhinitis in pigs (Harris \& Switzer, 1968; Goodnow, 1980). The disease state is recognised by severe changes in the nasal architecture of developing piglets, pneumonia and growth retardation (Harris \& Switzer, 1968). We have demonstrated that protection against $B$. bronchiseptica-mediated atrophic rhinitis correlates with the presence of an outer-membrane protein with a molecular mass of $68 \mathrm{kDa}$ as determined

* Author for correspondence Tel. (081) 658 9966, ext. 6506; fax. (081) 6500725

† Present address: Vaccine Research Unit, Medeva Group Research, Imperial College of Science, Medicine and Technology, London SW7 2AL, UK.

$\ddagger$ Present address: Department of Biochemistry, Imperial College of Science, Medicine and Technology, London SW7 2AL, UK.

Abbreviations: The designations P.68/P.94, P.69/P.93, P.70/P.95 refer to the pertactin family of outer-membrane proteins expressed in $B$. bronchiseptica, $B$. pertussis and $B$. parapertussis respectively with molecular masses of 68,69 and $70 \mathrm{kDa}$. The initial number (e.g. P.68) refers to the apparent molecular mass $(\mathrm{kDa})$ of the processed form of the antigen that appears on the bacterial surface, while the second number (e.g. P.94) refers to the molecular mass of the unprocessed precursor as inferred from the DNA sequence.

The nucleotide sequence reported in this paper has been submitted to the EMBL Database and has been assigned the accession number X54815. by SDS-PAGE (Novotny et al., 1985b). Antibodies to this $68 \mathrm{kDa}$ protein can be detected in high titre in protected piglets, while the titre is low or absent from non-protected animals (Novotny et al., 1985b). Furthermore, a naturally occurring mutant of $B$. bronchiseptica lacking the $68 \mathrm{kDa}$ protein is unable to protect piglets when used as a vaccine and is unable to induce pathological changes in infected piglets (Novotny et al., $1985 \mathrm{~b}$ ). Administration of a vaccine consisting of a purified preparation of the $68 \mathrm{kDa}$ protein to pregnant sows results in significant protection of the resulting piglets when challenged with virulent $B$. bronchiseptica (Kobisch \& Novotny, 1990). In addition, passively administered monoclonal antibody BB05 (Novotny et $a l ., 1985 a$, specific for the $68 \mathrm{kDa}$ protein) was able to prevent death from pneumonia and development of atrophic rhinitis in mice that had been aerosol-infected with a virulent strain of $B$. bronchiseptica.

The $68 \mathrm{kDa}$ protein is a member of an immunologically cross-reactive family of Bordetella spp. outermembrane proteins that are represented in Bordetella parapertussis as a $70 \mathrm{kDa}$ moiety (P.70) and in Bordetella pertussis as a $69 \mathrm{kDa}$ (P.69) species. The P.69 antigen has been demonstrated to be a protective antigen against $B$. pertussis infections in a mouse aerosol model (Shahin $e t$ al., 1990) and in the mouse intracerebral challenge model (Novotny et al., 1985a) and is currently under evaluation as a component of future acellular vaccines against 
whooping cough (Novotny et al., 1991; Romanos et al., 1991). P.69 has also been shown to be an agglutinogen (Brennan et al., 1988) that can promote attachment to certain eukaryotic cells via an Arg-Gly-Asp (RGD) tripeptide sequence (Leininger et al., 1991). Such sequences have been characterized for a number of eukaryotic cell-cell (Ruoslahti et al., 1988) and virus-cell (Fox et al., 1989) attachment processes. Because of the cell attachment behaviour of the P.69 antigen it has been renamed pertactin, the product of the prn gene. Nothing is known about the immunological properties of the P.70 antigen from $B$. parapertussis, although it shares high homology with the P.69 protein (Li et al., 1991; Charles et al., 1989) including a putative RGD binding site.

In this paper we report the cloning and characterization of the gene encoding the $68 \mathrm{kDa}$ antigen from $B$. bronchiseptica (P.68 pertactin) and show it to be highly homologous to its counterparts from $\boldsymbol{B}$. pertussis and $\boldsymbol{B}$. parapertussis. Expression of the full-length gene, capable of encoding a protein with a calculated molecular mass of $93996 \mathrm{Da}$, in Escherichia coli results in the appearance of a $68 \mathrm{kDa}$ form of the protein on the bacterial outer membrane. Native P.68 antigen can only be purified at low levels from cultures of $B$. bronchiseptica, but by utilizing a recombinant approach we hope to be able to produce larger samples of P.68 antigen that are completely uncontaminated by other $B$. bronchiseptica components. This will facilitate the understanding of both the molecular biological and immunological properties of this molecule.

\section{Methods}

Bacterial strains, plasmids and phage. B. bronchiseptica strain CN7531 was from the Wellcome culture collection (Wellcome Biotech, UK). $E$. coli $\mathrm{K} 12$ strains TG1 and HB101 were as previously described (Carter et al., 1985; Boyer \& Roulland-Dussoix, 1969). Cosmid pHC79 (Hohn \& Collins, 1980) was from Amersham International. Plasmid pKK2332 (Amann \& Brosius, 1985) and M13mp18 and M13mp19 (YanischPerron et al., 1985) were supplied by Pharmacia. The P.69 and P.70 expression plasmids pAYL1 and pBD845 have been described previously (Li et al., 1991). Plasmid pBSSKII+ (Bluescript) was from Stratagene. E. coli strains were grown in Luria broth (LB) or LB solidified with $1.6 \%(\mathrm{w} / \mathrm{v})$ agar (Miller, 1972). B. bronchiseptica was grown in Stainer-Scholte (Stainer \& Scholte, 1962) broth or medium as previously described (Novotny et al., 1985a).

DNA isolation and manipulations. B. bronchiseptica CN7531 chromosomal DNA was prepared as described previously (Hull et al., 1981). Plasmid and bacteriophage DNA were isolated and purified by standard methods (Maniatis et al., 1982). All DNA-modifying enzymes were from Gibco BRL.

Construction of a B. bronchiseptica genomic library. Cosmid pHC79 DNA was digested with BamHI and ligated with Sau3A-digested $B$. bronchiseptica DNA in the 40-50 kb size range as described previously (Charles et al., 1990). The gene bank was plated out and 480 randomly selected colonies transferred to microtitre plates as described previously (Charles et al., 1990). Colonies were transferred to Gene Screen
Plus hybridization membranes (Du Pont) and hybridized with an $\alpha^{32} \mathrm{P}$-labelled ClaI fragment of the prn gene encoding the P.70 protein from $B$. parapertussis (Li et al., 1991) as described previously.

Subcloning and DNA sequencing. Recombinant phage DNA was sequenced after ligation of specific restriction endonuclease fragments of cosmid into the vectors M13mp18 and M13mp19. Sequencing was carried out using universal primer, $\left[\alpha^{35} S\right] \mathrm{dATP}$ and both gradient and wedge gels (Biggin et al., 1983; Sanger et al., 1977). Some clones were sequenced with modified T7 DNA polymerase (Tabor \& Richardson, 1987) and 7-deaza-2-dGTP (Mizusawa et al., 1986) using a kit supplied by Pharmacia. Gaps in the sequence were filled in using synthetic oligonucleotides made on a MilliGen 7500 DNA synthesizer (Millipore, UK) as specific primers (Charles et al., 1986).

Amino acid sequencing and immunological characterization. P.68 pertactin was purified as described previously (Novotny et al., 1985b) and protein sequence determined by using an Applied Biosystems 470A gas-phase microsequencer. $E$. coli lysates harbouring recombinant P.68, P.69 and P. 70 protein were prepared by harvesting $5 \mathrm{ml}$ overnight cultures of $E$. coli TGl grown in L-broth harbouring either pBD881 (P.68), pAYL1 (P.69) or pBD845 (P.70). Cell pellets were washed once in L-broth and $0.1 \mathrm{OD}_{650}$ units were subjected to SDS-PAGE (Maniatis et al., 1982). Proteins were transferred to nitrocellulose by the method of Towbin et al. (1979). The monoclonal antibody BB05 (Montaraz et al., 1985; Novotny et al., 1985a) was used to detect P.68 protein using horse-radish-peroxidase-conjugated goat antimouse second antibody and 4-chloro-1-naphthol as substrate (Fairweather et al., 1986). To test for surface expression of recombinant P.68, slide agglutination assays were carried out as described previously ( $\mathrm{Li}$ et al., 1991).

\section{Results}

\section{Isolation of the gene encoding the P.68 antigen}

The $B$. bronchiseptica genomic library was screened by hybridization with a radioactively-labelled $1.8 \mathrm{~kb} \mathrm{ClaI}$ fragment of the prn gene encoding the P.70 antigen from B. parapertussis ( $\mathrm{Li}$ et al., 1991). Of the two cosmids returning a positive signal, one, designated pBD844, was selected for further analysis. Restriction mapping and Southern blotting experiments carried out on pBD844 demonstrated that the ClaI and SalI hybridization pattern of the prn gene from B. bronchiseptica was identical to that described for both $B$. pertussis (Charles et al., 1989) and B. parapertussis (Li et al., 1991). These ClaI and SalI fragments were therefore assumed to contain the entire prn gene encoding the P.68 pertactin and were cloned into Bluescript $\mathrm{pBSSKII}^{+}$to generate pBD875 (ClaI) and pBD856 (SalI); they were also cloned into M13mp18 and M13mp19 for DNA sequencing.

Nucleotide sequence of the prn gene encoding P.68: comparison with the equivalent genes from $B$. pertussis and $B$. parapertussis.

The DNA sequence was obtained initially from the $\mathrm{ClaI}$ and Sal I fragments cloned into M13 and using universal 


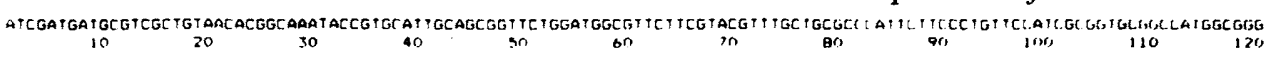

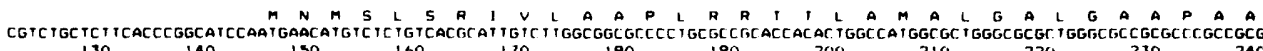

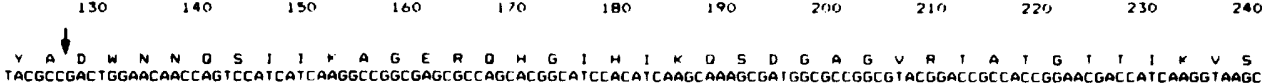

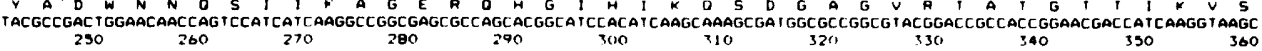

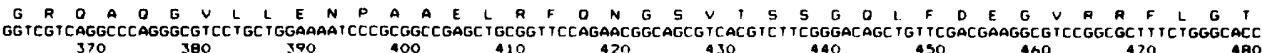

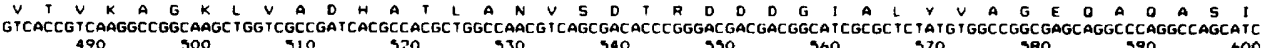

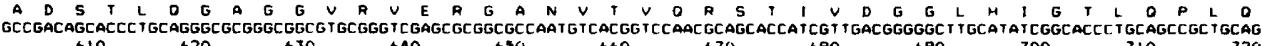

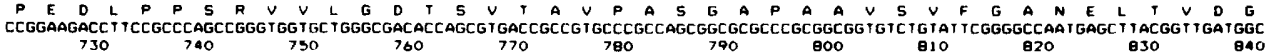

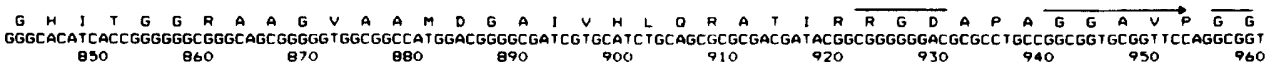

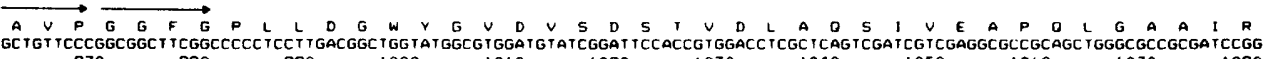

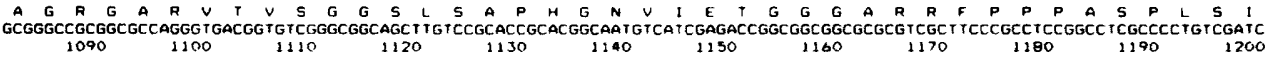

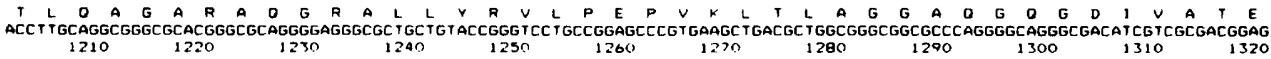

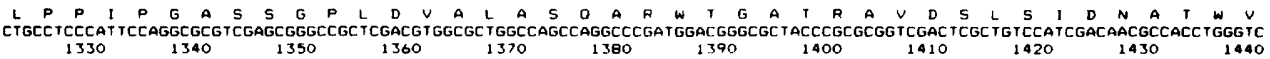

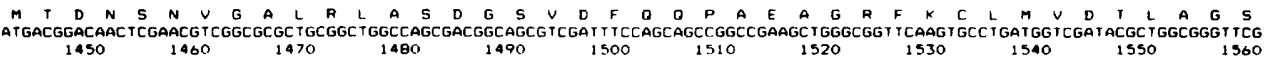
G L L F P M N N V F F A

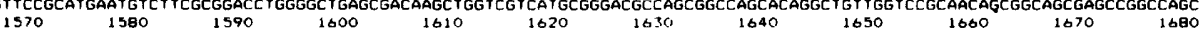

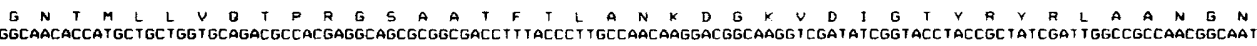
$\begin{array}{llllllllllll}1690 & 1700 & 1710 & 1720 & 1730 & 1740 & 1750 & 1760 & 1770 & 1780 & 1790 & 1800\end{array}$

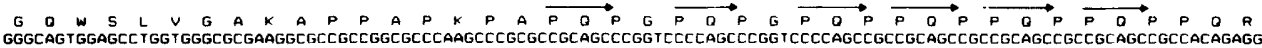

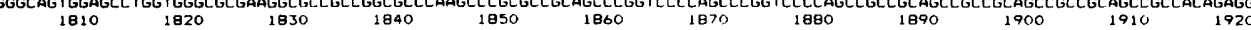

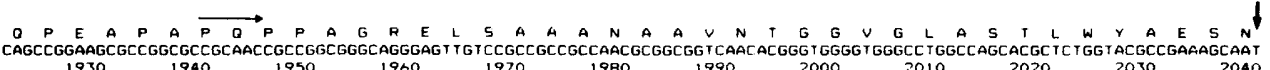

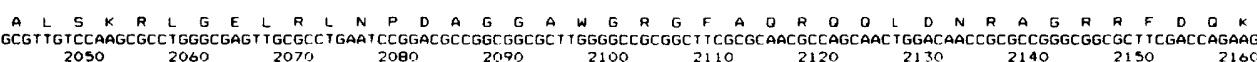

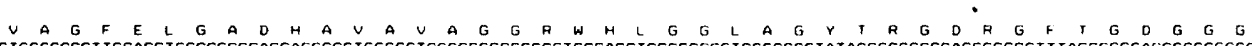

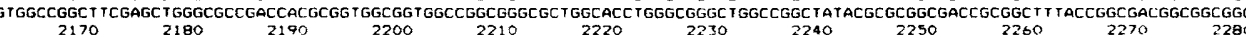

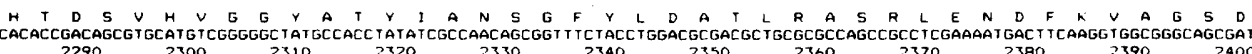
G Y A V V
G G G K K Y V R

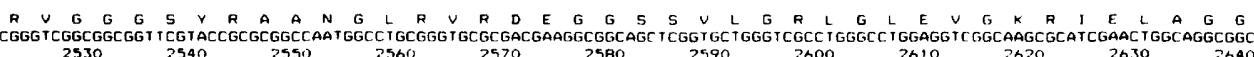

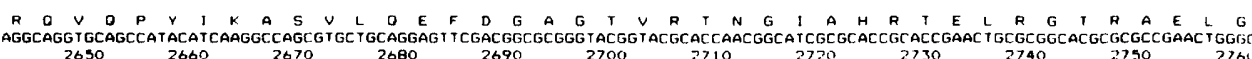

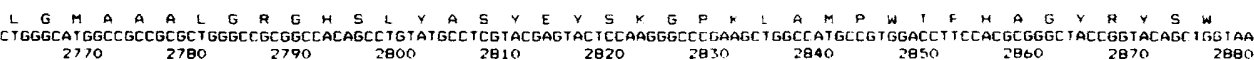

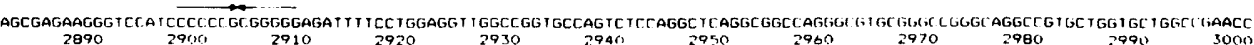

Fig. 1. DNA sequence of the prn gene encoding the P.68 pertactin from B. bronchiseptica. Downward arrows indicate the sites of two possible protein cleavage regions that result in the production of the mature polypeptide. Arrows over protein sequence denotes two protein repeat motifs: (i) (GGXXP) ${ }_{3}$ encoded by nucleotides $939-983$ and (ii) (PQP) ${ }_{7}$ encoded by nucleotides $1852-1947$. An RGD tripeptide sequence encoded by nucleotides $922-930$ that occurs in the surface-exposed processed P.68 form of the protein is shown overlined. An additional RGD tripeptide motif occurs between residues 2245-2253 within the C-terminal fragment of P.94 that is clipped off during the processing of P.68. An inverted repeat followed by a run of T-residues, resembling a rho-independent transcription terminator, is shown between residues $2898-2909$. 


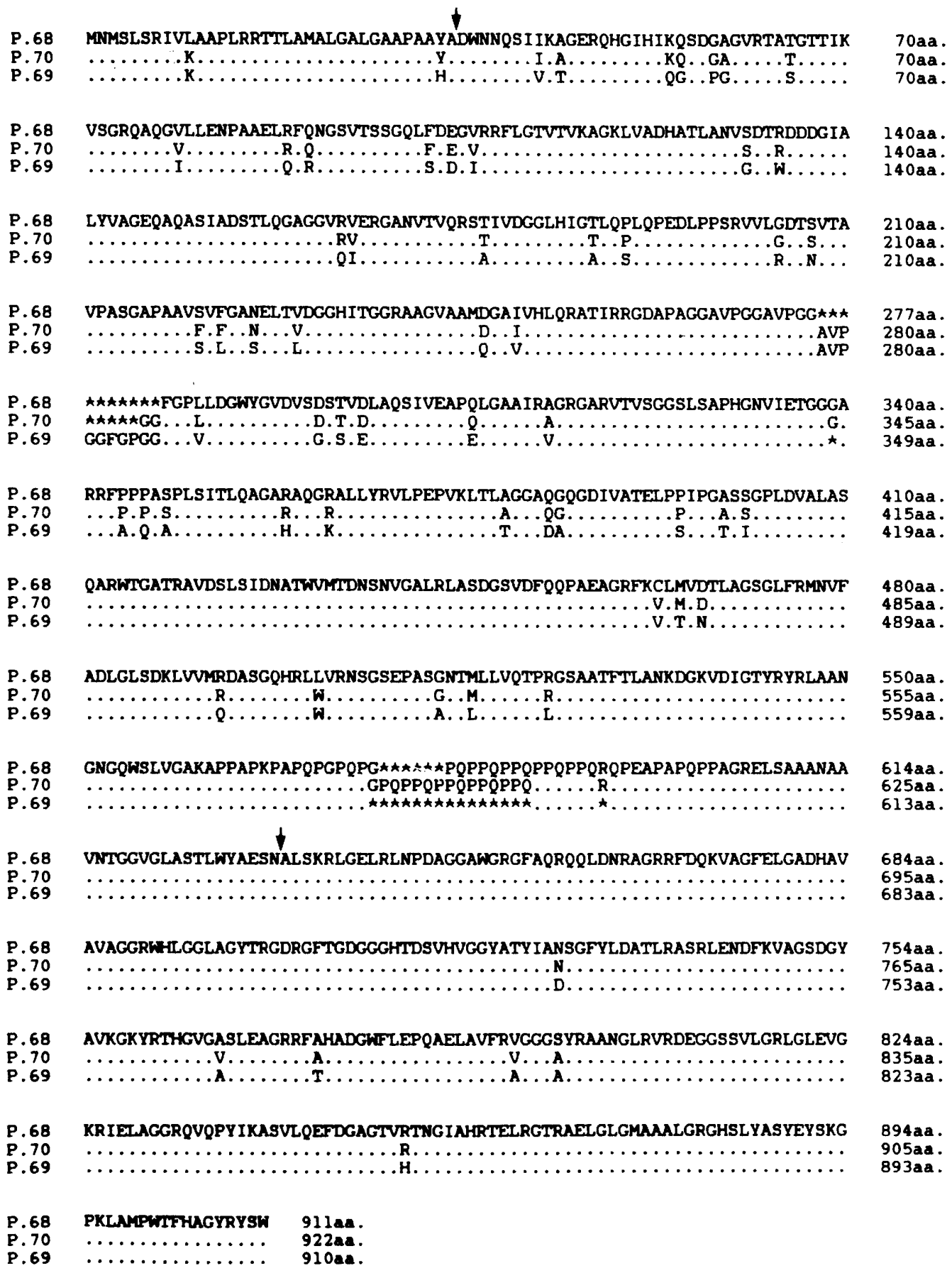

Fig. 2. Protein sequence alignment of the P.68, P.70 and P.69 pertactins from B. bronchiseptica, B. parapertussis and B. pertussis, respectively. Downward arrows represent the position of likely protein cleavage sites. ${ }^{*}$, Missing residue within the alignment. The P.69 sequence has two corrections from the version published in Charles et al., 1989; these are (i) at amino acid 264, where proline replaces leucine, and (ii) at amino acid 322 where serine replaces proline. These corrections have been reported to the sequence data bases.

primer; the overlapping sequence was compiled using a set of synthetic oligonucleotides as specific sequence primers. Computer analysis of the DNA sequence (Fig. 1) demonstrates that the ORF for the prn gene of P.68 pertactin is capable of encoding a protein with a molecular mass of $93996 \mathrm{Da}$ (P.94). The molecular mass of the mature protein found on the surface of $B$. bronchiseptica is, however, $68000 \mathrm{Da}$ as judged by SDSPAGE, suggesting that this molecule is a processed form of the larger precursor. By comparison with the P.69 antigen, this processing is likely to involve the removal of both $\mathrm{N}$-terminal and $\mathrm{C}$-terminal sequences. $\mathrm{N}$-terminal 
protein sequencing of purified preparations of $\mathrm{P} .68$ from $B$. bronchiseptia gave the sequence Asp-Trp/Gln-AsnAsn-Gln-Gln/Ser-Ile-Xaa-Lys-Ala. This sequence, despite having three regions of ambiguity, aligns with amino acid residues 35-44 in Fig. 2 and confirms that in common with the P.70 and P.69 sequences, a signal peptide is cleaved in the maturation process of P.68 pertactin. Cleavage of this signal peptide, of between 32 or 34 amino acid residues depending on which ATG initiation codon is used, occurs after the sequence AlaTyr-Ala, which is in agreement with the Ala-Xaa-Ala motif reported to be recognized by $E$. coli signal peptidases (Perlman \& Halvorson, 1983). Towards the C-terminus of the P.68 protein at residues $602-603$ (numbering the Asp produced after signal peptide cleavage as residue 1) is a dibasic pair of amino acids, Lys-Arg, that occur in the same position, and are flanked by identical residues, as are found in the P.69 pertactin from $B$. pertussis. This Lys-Arg sequence in $B$. pertussis was originally identified as a putative cleavage site involved in the production of the mature form of the protein (Makoff et al., 1990). More recently, Capiau et al. (1990) have reported that purified preparations of P.69 have a C-terminal Asn residue. This Asn residue at amino acid residue position 597 is closely positioned to the Lys-Arg motif in the sequence Asn-Ala-Leu-SerLys-Arg (Fig. 2). The precise processing events responsible for the generation of this C-terminal sequence are still unknown.

A comparison of the deduced protein sequences for the P.68, P.69 and P.70 proteins (Fig. 2) demonstrates the high degree of homology between the proteins. A comparison between the P.68 and P.70 proteins shows only 17 amino acid differences, while a similar comparison between P.68 and P.69 shows 80 differences and between P.69 and P.70 there are 79 differences. The majority of amino acid differences between the three deduced protein sequences occur in the number of repeat units in the two families of repeat sequences present in all three proteins. Thus, P.68 has three copies of the GlyGly-Xaa-Xaa-Pro repeat while P.70 has four and P.69 five. Similarly, P.68 has seven Pro-Gin-Pro repeats, P.70 has nine and P.69 has five. These findings suggest that the P.68 sequence from B. bronchiseptica and the P.70 sequence from $B$. parapertussis are more closely related to each other than either are to the P.69 sequence from $B$. pertussis. The finding of close sequence homology between $B$. bronchiseptica and $B$. parapertussis is in agreement with the evolutionary trees produced by Altschul (1989), based on a re-analysis of the sequence of the pertussis toxin operons from all three Bordetella species (Arico et al., 1987).

Examination of the first $140 \mathrm{bp}$ of the DNA sequence in Fig. 1 shows that there are no good fits with either the consensus ribosome binding site (Shine \& Dalgarno, 1975 ) or consensus promoter elements identified for $E$. coli genes (Rosenberg \& Court, 1979). In common with the genes encoding both P.68 and P.69, there is an inverted repeat after the stop codon, and then a run of $T$ residues. This sequence resembles the rho-independentlike terminator that is also found at the end of the $B$. pertussis ptx operon (Charles et al., 1989).

\section{Heterologous expression of $P .68$ pertactin in E. coli}

Cosmid pBD844 harbouring the $B$. bronchiseptica prn gene was unable to direct the expression of $P .68$ pertactin in $E$. coli. To express the gene in $E$. coli, the entire structural gene was cloned into the expression plasmid pKK233-2. Fig. 3 outlines the expression strategy; an EcoRI-EcoRV fragment comprising the $5^{\prime}$ end of P.68 prn from plasmid pBD875 was ligated into EcoRVEcoRI digested pBD856 (containing the $3^{\prime}$ end of P.68 prn) to generate $\mathrm{pBD} 876$ containing the entire structural gene. Plasmid pBD876 was digested with AflIII-HindIII and ligated with $N c o$ I-HindIII-digested pKK233-2. This ligation mixture was used to transform $E$. coli TG1 and transformants expressing P.68 pertactin identified by their ability to cross-react with the mAb BB05 in protein dot-blots.

Colonies returning a positive signal were isolated and plasmid minipreps carried out to verify that a full-length insert had been cloned. One such plasmid, pBD881, was selected for further study. Fig. 4 shows the result of a Western blot of an SDS-PAGE gel of $E$. coli TG1 harbouring (1) pBD845 (P.70/P.95); B. parapertussis, (2) pAYL1 (P.69/.93); B. pertussis, (3) pBD881 (P.68/P.94); $B$. bronchiseptica and (4) pKK233-2. The arrows represent the position of bands corresponding to proteins with molecular masses of $70 \mathrm{kDa}$ ( $B$. parapertussis), $69 \mathrm{kDa}$ (B. pertussis) and $68 \mathrm{kDa}$ (B. bronchiseptica). For both the plasmids expressing the P.70/P.95 and P.69/P.93 proteins, larger bands corresponding to the full-length $95 \mathrm{kDa}$ and $93 \mathrm{kDa}$ species are present in addition to a large number of lower molecular mass bands. Surprisingly, the P.68 expression construct does not produce a detectable $94 \mathrm{kDa}$ higher molecular mass band, but instead produces a pair of stronger bands at around $69 \mathrm{kDa}$ and $68 \mathrm{kDa}$. The pattern of bands produced for P.69 and P.70 pertactin expression differs from that reported in our earlier work ( $\mathrm{Li}$ et al., 1991). This discrepancy may be due to the different growth conditions used in preparing the lysates for Western blotting. The constructs pBD881, pBD845 and pAYL1 direct the expression of P.68, P.69 and P.70, respectively, under the control of the tac promoter and IPTG induction. In preliminary experiments, the use of IPTG 

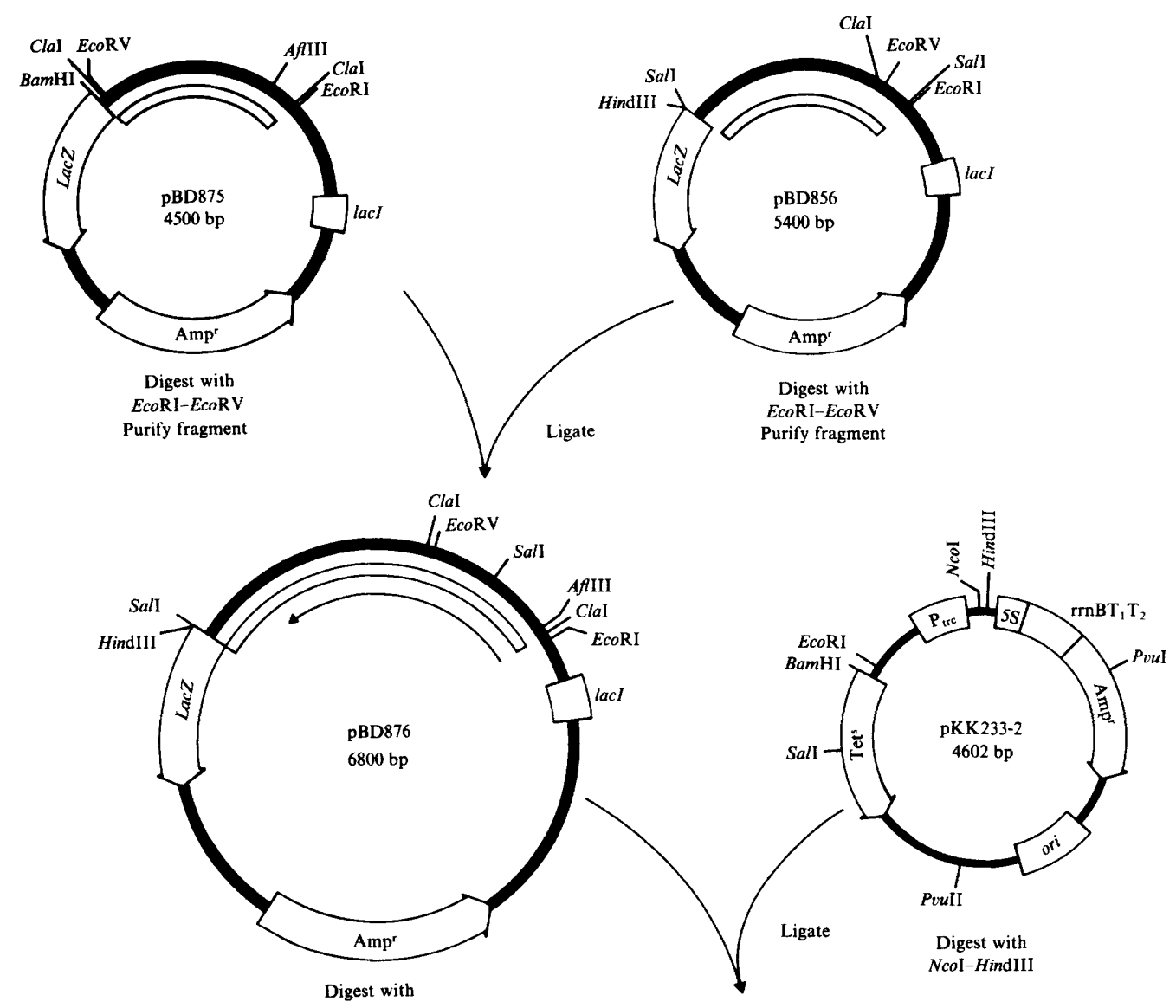

AfIII-HindIII

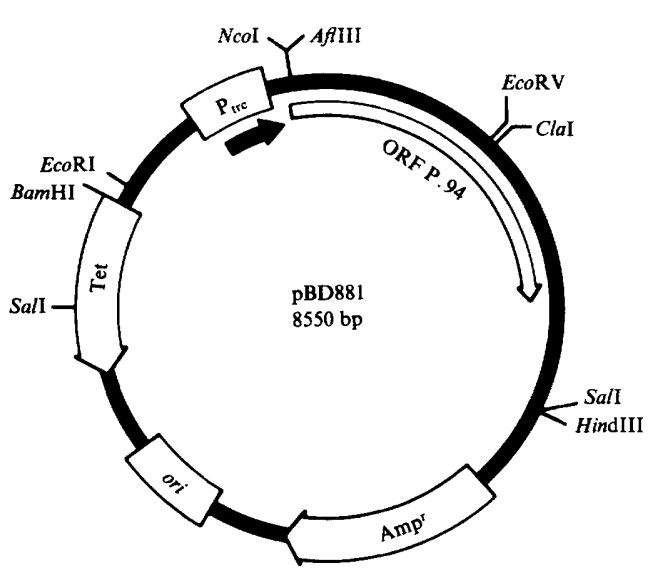

Fig. 3. Line drawing representing the strategy used to generate the P.68 expression plasmid pBD881. Plasmids pBD875 and pBD856 contain the $5^{\prime}$ and $3^{\prime}$ sections of the gene encoding $B$. bronchiseptica prn, respectively, and were used to generate the full-length gene encoding P.94. This full-length (non-expressing) gene harboured by pBD876 was excised by digestion with $A f$ III and $H i n d I I I$ and ligated with NcoI-HindIII-digested pKK233-2 to generate the P.68 expressing plasmid pBD881.

to induce pertactin expression led to the accumulation of unprocessed P.94, P.93 and P.95 forms of the proteins as insoluble inclusion bodies (data not shown). In our previous work (Li et al., 1991) lysates were prepared from bacteria grown in M9 minimal medium to avoid this overexpression problem. The lysates used in this study and shown in Fig. 4 were prepared from bacteria grown in L-broth. The partial induction of the promoters under these conditions leads to the accumulation of full-length forms of P.69/93 and P.70/95 that are not processed.

To test whether or not the P.68 protein was expressed on the surface of $E$. coli, slide agglutination assays were carried out using both monoclonal antibody BB05 and polyclonal anti-P.69 antibody (Li et al., 1991). Agglutination occurred just as rapidly with $E$. coli harbouring pDB881 as with vir ${ }^{+} B$. bronchiseptica, suggesting that the 


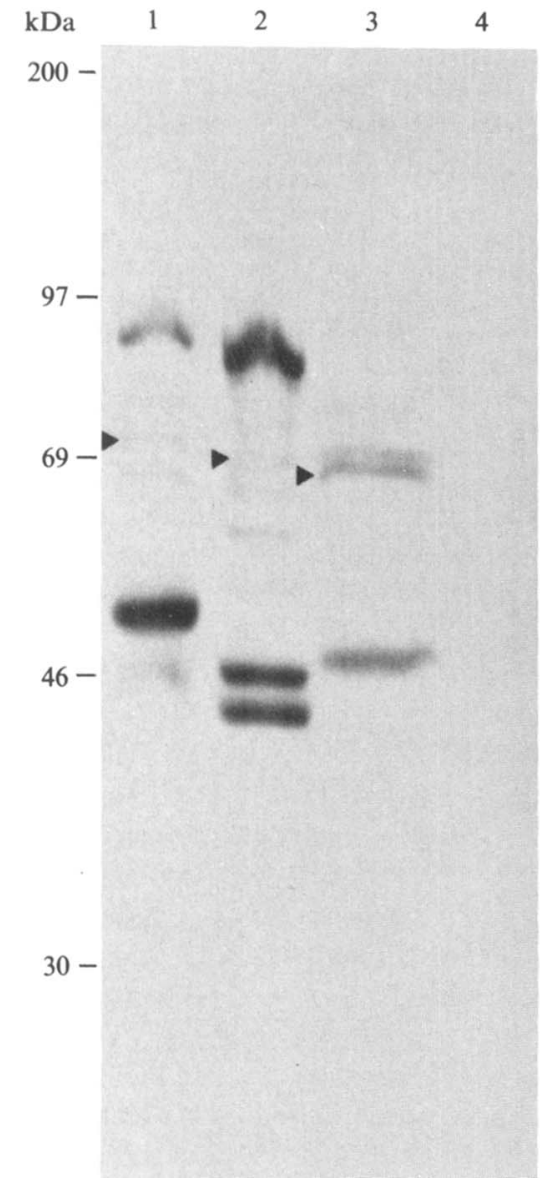

Fig. 4. Western blot showing the expression of the pertactin family of proteins in $E$. coli TG1. Samples were prepared as described in Methods and reacted with the monoclonal antibody BB05. Lanes: 1 , P.70/P.95 pertactin; 2, P.69/P.93 pertactin; 3, P.68/P.94 pertactin; 4, (negative control), pKK233-2. Arrows indicate positions of protein bands corresponding to the $70 \mathrm{kDa}, 69 \mathrm{kDa}$ and $68 \mathrm{kDa}$ species. There is no signal from the negative control (track 4). In lanes 1 and 2, heavy bands can be seen just below the $97 \mathrm{kDa}$ molecular mass marker. These bands probably correspond to the full-length protein precursors for P.70 and P.69. By contrast, there is no apparent band for the full-length P.68 precursor. For all three proteins, lower molecular mass bands cross-reacting with BB05 monoclonal antibody indicate that the proteins are substantially degraded in $E$. coli.

heterologous protein is surface-located. Both the positive control strains of $E$. coli expressing P.69 (pAYL1) and P.70 (pBD845) on their surface were able to demonstrate agglutination (Li et al., 1991).

\section{Discussion}

Protection against $B$. bronchiseptica-mediated atrophic rhinitis in animals correlates with the presence of a $68 \mathrm{kDa}$ protein (Novotny et al., 1985b). In this paper we report the cloning, sequencing and expression of this protective antigen in $E$. coli. The $B$. bronchiseptica P.68 antigen belongs to a family of outer membrane immunologically cross-reactive proteins. In $B$. pertussis, a homologous protein has been characterized with a molecular mass of $69 \mathrm{kDa}$, as judged by PAGE, and has been the subject of much recent study as a potential candidate for inclusion in new generations of acellular whooping cough vaccines (Charles et al., 1989, 1991; Shahin et al., 1990; Novotny et al., 1991; Romanos et al., 1991; Roberts et al., 1992). So far there has been little study of the equivalent P.70 protein from B. parapertussis, although we have recently isolated and sequenced the gene encoding the protein (Li et al., 1991). A comparison between the deduced sequences for the P.68, P.69 and P.70 pertactins reveals a high degree of homology, with the $B$. parapertussis and $B$. bronchiseptica proteins being more similar to each other than to the P.69 protein from $B$. pertussis. The main regions of sequence divergence between the three proteins occur in the number of repeats within the repeated regions. The region spanning the Pro-Gln-Pro family of repeats has been demonstrated to be the immunodominant part of the P.69 molecule (Charles et al., 1991). Differences in this region may have significance in determining the degree of immunological cross-reactivity between the different molecules, and may account for the observation that sera from piglets that cross-reacted in ELISA with preparations of P.68 failed to react with P.69 (Kobisch \& Novotny, 1990) despite the high degree of homology between the proteins.

It has been demonstrated that the P.69 protein has the ability to bind to $\mathrm{CHO}$ cells in culture. This binding is mediated, at least in part, by an Arg-Gly-Asp (RGD) tripeptide sequence; a mechanism that has been characterized for a variety of adhesive proteins (Ruoslahti, 1988 ) including $B$. pertussis filamentous hemagglutinin (Relman et al., 1990) and may suggest that P.69 has a role in bacterial adhesion. The finding of a similar RGD sequence in the P.68 pertactin also suggests that this protein may have a role in bacterial adhesion, and thus play a role in virulence. The expression of the P.68 protein on the surface of $E$. coli should enable us to produce recombinant protein that is uncontaminated by other $B$. bronchiseptica components for both immunological and cell-adhesion evaluation.

We thank Hugh Spence for making the oligonucleotides used in the sequencing strategy, Martin Merrett for $\mathrm{N}$-terminal protein sequencing and Tina Silva for typing the manuscript.

\section{References}

Altschul, S. F. (1989). Evolutionary trees for the genus Bordetella. Journal of Bacteriology 171, 1211-1213.

Amman, E. \& Brosius, J. (1985). 'ATG' vectors for regulated high-level expression of cloned genes in Escherichia coli. Gene 40, 183-190. 
Arico, B., Gross, R., Smida, J. \& Rappuoli, R. C. (1987). Evolutionary relationships in the genus Bordetella. Molecular Microbiology 1, 301-308

BigGin, M. D., Gibson, T. J. \& Hong, G. F. (1983). Buffer gradient gels and $\alpha^{35}$-S label as an aid to rapid DNA sequence determination. Proceedings of the National Academy of Sciences of the United States of America 80, 3963-3965.

BOYER, H. W. \& Roulland-Dussoix, D. (1969). A complementation analysis of the restriction and modification of DNA in Escherichia coli. Journal of Molecular Biology 41, 459-465.

Brennan, M. J., Zhong, M. L., Cowell, J. L., Bisher, M. E., Steven, A. C., Novotny, P. \& MaNClarK, C. R. (1988). Identification of a 69-kilodalton non-fimbrial protein as an agglutinogen of Bordetella pertussis. Infection and Immunity 56, 3189-3195.

Capiau, C., Carr, S. A., Hemling, M. E., Plainchamp, D., Conrath, K., Hauser, P., Simoen,, E., Comberbach, M., Roelants, P., Desmons, P., Permanne, P. \& Petre, J. O. (1990). Purification, characterisation and immunological evaluation of the $69-\mathrm{kDa}$ outer membrane protein of Bordetella pertussis. In Proceedings of the Sixth International Symposium on Pertussis [DHHS Publication no. (FDA) 90-1164], pp. 75-86. Edited by C. R. Manclark. Bethesda, Maryland: Department of Health and Human Services, United States Public Health Service.

Carter, P., Bedouell, H. \& Winter, G. (1985). Improved oligonucleotide site directed mutagenesis using M13 vectors. Nucleic Acids Research 13, 443-444.

Charles, I. G., Keyte, J., Brammar, W. J., Smith, M. \& Hawkins, A. R. (1986). The isolation and nucleotide sequence of the complex AROM locus of Aspergillus nidulans. Nucleic Acids Research 14, 2201-2213.

Charles, I. G., Dougan, G., Pickard, D., Chatfield, S., Smith, M., Novotny, P., Morrissey, P. \& Fairweather, N. F. (1989). Molecular cloning and characterization of protective outer membrane protein P.69 from Bordetella pertussis. Proceedings of the National Academy of Sciences of the United States of America 86, 3554-3558.

Charles, I. G., Lamb, H. K., Pickard, D., Dougan, G. \& Hawkins, A. R. (1990). Isolation, characterization and nucleotide sequences of the $a r o C$ genes encoding chorismate synthase from Salmonella typhi and Escherichia coli. Journal of General Microbiology 136, 353-358.

Charles, I. G., Li, J., Roberts, M., Beesley, K., Romanos, M., Pickard, D. J., Francis, M., Campbell, D., Dougan, G., Brennan, M. J., Manclark, C. R., Au Jensen, M., Heron, I., ChubB, A., Novotny, P. \& FaIR Weather, N. F. (1991). Identification and characterisation of a protective immunodominant B-cell epitope of pertactin from Bordetella pertussis. European Journal of Immunology 21, 1147-1153.

Fairweather, N. F., Lyness, V. A., Pickard, D., Allen, G. \& Thomson, R. O. (1986). Cloning, nucleotide sequencing and expression of tetanus toxin fragment $\mathrm{C}$ in Escherichia coli. Journal of Bacteriology 165, 21-27.

Fox, F., Parry, N. R., Barnett, P. V., McGinn, B., Rowlands, D. J. \& BROWN, F. (1989). The cell attachment site on Foot-and-Mouth disease virus includes the amino acid sequence RGD (ArginineGlycine-Aspartic Acid). Journal of General Virology 70, 625-637.

GoodNow, R. A. (1980). Biology of Bordetella bronchiseptica. Microbiological Reviews 44, 722-738.

HARRIS, D. L. \& SwITZER, W. P. (1968). Turbinate atrophy in young pigs exposed to Bordetella bronchiseptica, Pasteurella multocida and combined inoculum. American Journal of Veterinary Research 29, 777-785.

HoHn, B. \& Collins, J. (1980). A small cosmid for efficient cloning of large DNA fragments. Gene 11, 291-298.

Hull, R. A., Gill, R. E., Hsu, P., Minshew, B. H. \& Falkow, S. (1981). Construction and expression of recombinant plasmids encoding type 1 or D-mannose resistant pili from a urinary tract infection Escherichia coli. Infection and Immunity 33, 933-938.

KOBISCH, M. \& NovOTNY, P. (1990). Identification of a 68-kilodalton outer membrane protein as the major protective antigen of Bordetella bronchiseptica by using specific-pathogen-free piglets. Infection and Immunity 58, 352-357.
Leininger, E., Roberts, M., Kenimer, J. G., Charles, I., FairWeather, N., Novotny, P. \& BrenNan, M. J. (1991). Pertactin, an Arg-Gly-Asp-containing Bordetella pertussis surface protein that promotes adherence of mammalian cells. Proceedings of the National Academy of Sciences of the United States of America 88, 345-349.

Li, J. L., Dougan, G., Novotny, P. \& Charles, I. G. (1991). P.70 pertactin an outer membrane protein from Bordetella pertussis: cloning, nucleotide sequence and surface expression in Escherichia coli. Molecular Microbiology 5, 409-417.

Makoff, A. J., Oxer, M. D., Ballantine, S. P., Fairweather, N. F. \& Charles, I. G. (1990). Protective surface antigen P.69 of Bordetella pertussis: its characterization and very high level expression in Escherichia coli. Bio/Technology 8, 1030-1033.

Maniatis, T., Fritsch, E. E. \& SAmbrook, J. (1982). Molecular Cloning: a Laboratory Manual. Cold Spring Harbor, NY: Cold Spring Harbor Laboratory.

Miller, J. M. (1972). Experiments in Molecular Genetics. Cold Spring Harbor, NY: Cold Spring Harbor Laboratory.

MontaRAZ, J. A., Novotny, P. \& IVANYI, J. (1985). Identification of a 68-kilodalton protective antigen from Bordetella bronchiseptica. Infection and Immunity 47, 744-751.

Mizusawa, S., Nishimura, S. \& SeEla, F. (1986). Improvements of the dideoxy chain termination method of DNA sequencing by use of deoxy-7-deazaguanosine triphosphate in place of dGTP. Nucleic Acids Research 14, 1319-1324.

Novotny, P., ChubB, A. P., Cownley, K., Montaraz, J. A. \& BeEsleY, J. E. (1985a). Bordetella adenylate cyclase: a genusspecific protective antigen and virulence factor. In Proceedings of the Fourth International Symposium on Pertussis. Development of Biological Standards 61, 27-41.

Novotny, P., Kobisch, M., Cownley, K., ChubB, A. P. \& MonTARAz, J. A. (1985b). Evaluation of Bordetella bronchiseptica vaccines in specific-pathogen-free piglets with bacterial cell surface antigens in enzyme-linked immunosorbent assay. Infection and Immunity 50, 190-198.

Novotny, P., Chubb, A. P., Cownley, K. \& Charles, I. G. (1991). Biological and protective properties of the $69-\mathrm{kDa}$ outer membrane protein of Bordetella pertussis: a novel formulation for an acellular pertussis vaccine. Journal of Infectious Diseases 164, 114-122.

Perlman, D. \& Halvorson, H. O. (1983). A putative signal peptidase recognition site and sequence in eukaryotic and prokaryotic peptides. Journal of Molecular Biology 167, 391-409.

Pitrman, M. (1984). Genus Bordetella. In Bergey's Manual of Systematic Bacteriology, vol. I, pp. 388-393. Edited by N. R. Kreig, J. G. Holt. Baltimore: Williams \& Wilkins.

Relman, D., Toumanen, E., Falkow, S., Golenbock, D. T., SAKKONEN, K. \& WRIGHT, S. D. (1990). Recognition of a bacterial adhesin by an integrin: macrophage CR3 $\left(\mathrm{MB}_{2}, \mathrm{CD} 1 \mathrm{~b} / \mathrm{CD} 18\right)$ binds filamentous hemagglutinin of Bordetella pertussis. Cell 61, 1371-1382.

Roberts, M., Tite, J. P., Fairweather, N. F., Dougan, G. \& Charles, I. G. (1992). Recombinant P.69/Pertactin: immunogenicity and protection of mice against Bordetella pertussis. Vaccine 10, 43-48.

Romanos, M. A., Clare, J. J., Beelsey, K. M., Rayment, F. B., Ballantine, S. P., Makoff, A. J., Dougan, G., Fairweather, N. F. \& Charles, I. G. (1991). Recombinant Bordetella pertussis pertactin (P.69) from the yeast Pichia pastoris : high-level production and immunological properties. Vaccine 9, 901-906.

ROSENBERG, M. \& COURT, D. (1979). Regulation sequences involved in the promotion and termination of RNA transcription. Annual Review of Genetics 13, 319-353.

RUOSLAHTI, E. (1988). Fibronectin and its receptors. Annual Review of Biochemistry 57, 375-413.

SANGeR, F., Nicklen, S. \& Coulson, A. R. (1977). DNA sequencing with chain terminating inhibitors. Proceedings of the National Academy of Sciences of the United States of America 71, 5463-5467.

Shahin, R. D., Brennan, M. J., LI, Z. M., Meade, B. D. \& MANCLARK, C. R. (1990). Characterization of the protective capacity and immunogenicity of the $69 \mathrm{kD}$ outer membrane protein of Bordetella pertussis. Journal of Experimental Medicine 171, 63-73. 
Shine, J. \& Dalgarno, L. (1975). Determinant of cistron specificity in bacterial ribosomes. Nature, London 254, 34-38.

Stainer, D. W. \& SCholte, M. J. (1962). A simple chemically defined medium for the production of phase I Bordetella pertussis. Journal of General Microbiology 63, 211-220.

TABOR, S. \& RICHARDSON, C. C. (1987). DNA sequence analysis with a modified bacteriophage T7 polymerase. Proceedings of the National Academy of Sciences in the United States of America 84, 4767-4771.
Towbin, J., Staehelin, R. \& Gordon, J. (1979). Electrophoretic transfer of proteins from polyacrylamide gels to nitrocellulose sheets: procedures and some applications. Proceedings of the National Academy of Sciences of the United States of America 76, 43504354.

Yanisch-Perron, C., Vieira, J. \& Messing, J. (1985). Improved M13 phage vectors and host strains: nucleotide sequences of the M13mp18 and pUC19 vectors. Gene 33, 103-119. 